\title{
The phenomenon of "abuse of right" in the context of the problems of finding the methodological foundations of modern legal science
}

\author{
Sergey Vladimirovich Vasiliev", Elena Valentinovna Zykina, Boris Viktorovich Zykin, \\ Vladimir Mitrofanovich Sapogov, and Vasily Petrovich Sidorov
}

Pskov State University, Department of State and Legal Disciplines and Theory of Law, Institute of Law, Economics and Management, Pskov, Russia

\begin{abstract}
The purpose of this work is to identify new aspects of the identification of signs of "abuse of right" and to strengthen the ideas about this phenomenon as an independent one, which has not only a negative meaning, but also allows to detect new (non-traditional) directions of effective improvement of the legal space of the country, associated with a certain adjustment of views on the regulatory properties (possibilities) of the legal form of law. The authors provided a comprehensive use of various scientific methods, among which the comparative legal method, formallogical, dialectical, allowed to obtain new knowledge about the object of research. In the course of the work a non-standard methodological approach to the study of the phenomenon of "abuse of right" was tested, which allowed to identify and present new content elements (characteristics) of this phenomenon. This broadened and deepened the concept, taking a step toward a convincing argument for its independent (broad) meaning. The novelty of the work is due to the contribution to the theory of law, which creates prerequisites for the further conceptual study of the phenomenon of "abuse of right".
\end{abstract}

Keywords: legal theory, law, democracy, constitutional law

\section{Introduction}

In the present circumstances, it becomes clear that there is a different methodological approach to assessing the role and importance of the problem of abuse of rights and the need to study it in a broad sense. We cannot agree with the opinion that this concept has no independent content, reducing it to a kind of "valve" used in the rarest situations in life. This distorts the ideas about the relationship between the most important legal categories (right and law), which reduces the ability to effectively use the legal potential of our country for the quality of the process of development of society.

Changes in modern society associated with the development of information technology and the "virtual" nature of relations can have a significant impact not only on the regulatory

*Corresponding author: profi.60@mail.ru 
role and limits of law, but also on its very image, the ratio of forms of expression and legal reality in general. The need to change methodological approaches to comprehending the legal phenomena of reality, which are increasingly difficult to fully explain with the help of traditional research tools of positivist-ethatist nature, obviously dominant in the "official" legal understanding, is gradually realized.

The problem of abuse of rights is discussed in Russian legal science, there are different points of view on the legal nature of this phenomenon, but the general theory of law has not developed a unified understanding of its legal essence.

Researchers hold different, even diametrically opposite positions, from considering this phenomenon as a type of lawful activity [1], to recognizing the abuse of rights as a type of offense [2]. In this connection, one cannot but agree with the view that virtually every significant doctrinal field presents serious precedents operating in contradiction [3]. The dialectical method of the unity and struggle of opposites as a tool for grasping the realities of reality is once again in great demand.

The proposed study aims to expand the ideas about the signs of "abuse of law" in their dialectical relationship, as an ambiguous independent phenomenon, the potential of which can be used for the development of the legal system of the country.

\section{Methods}

The methodological approach, which deepens and systematizes the views on the substantive characteristics of the "abuse of right", which objectively initiates a discussion of the resource content of this phenomenon as a positive tool for the transformation of the legal space of Russia has been applied. The authors of the article used a variety of methods of scientific research, the use of which, based on a dialectical approach, allowed us to successfully emphasize new aspects of the problem of abuse of rights. Also provided a comprehensive use of various scientific methods, among which the comparative legal method, formal-logical, dialectical, allowed to obtain new knowledge about the object of research.

In the course of the work, we approbated a non-standard methodological approach to the study of the phenomenon of "abuse of right", which allowed us to identify and present new content elements (characteristics) of this phenomenon, which expanded and deepened this concept, making a step towards convincing argumentation of its self-sufficient (broad) meaning.

\section{Results}

The points of view revealed in the scientific literature seem to be somewhat limited. "Abuse of law" should be considered more broadly. Perhaps as a kind of "disease" of the legal system of the country as a whole, which should be "treated", significantly changing the approaches to legal understanding, transforming them in the direction of an adequate reflection of reality, inevitably correcting the methodological foundations of modern jurisprudence.

It seems to us that in modern Russia one of the main conditions provoking the "abuse of law" is that the legislative form is used somewhat monopolistically. The law is applied in a total way to solve absolutely all issues, without thinking about the natural, objective limitation of the regulatory possibilities of this form of law. The legislator, "abusing the right", uses only the supreme legal force of the law, i.e. its peculiar categorical "authority" as the main, binding regulator. At the same time, the substantive side of the law can be qualitatively low, non-legal, not in the interests of the general population of the country and the individual average citizen. 


\section{Discussion}

Based on the understanding of the abuse of rights as a type of offense, Gribanov presents a judgment on the attribution of this phenomenon to a special type of civil offense [2]. A similar point of view is presented in the studies of civil lawyers, who define this phenomenon as a specific form of violation of the principle of implementation of civil rights [4]. Probably close to this, but more general, is the point of view of Akchurin, who connects the abuse of right with the infliction of harm [5].

The fact of presence or absence of a definition of this phenomenon in the legislation is important for identification of the signs of abuse of rights. Balayan and Gatsko, when studying the problems of abuse of rights in the electoral process, note the specificity of this institution, which consists in the absence of its definition at the legislative level [6]. It is possible to agree with this point of view partially, since in the Russian legislation the abuse of rights is mentioned. For example, Stepkin [7] finds the use of this conceptual construction in clause 3 of article 11 of Federal Law No. 59-FZ dated May 2, 2006 "On the procedure to consider appeals of citizens of the Russian Federation" which allows to leave a citizen's appeal without an answer and inform him about the inadmissibility of abuse of right [8]. In addition, this author, summarizing the legislative definitions of Part 3 of Article 17 of the Constitution of the Russian Federation, Part 2 of Article 10 of the Convention for the Protection of Human Rights and Fundamental Freedoms, Articles 1 and 10 of the Civil Code of the Russian Federation, concludes that they contain a certain common formula that allows to identify signs of the state of malice: by exercising his rights, a citizen allows to violate the rights and freedoms of others, acts in bad faith [7].

Abuse of rights is most typical for civil legal relations, as they are the freest, allow some "liberties" of right holders within their subjective rights. For their regulation, the requirement of good faith is involved, without which it is difficult to ensure the orderly nature of the relations of the participants for a fair balance of their interests.

In our view, this is an example of a conflict with the growing diversity of manifestations of reality in need of "non-legal" means of regulation, which is mistakenly perceived as a violation of the right (law), which in reality is a manifestation of the natural limitations of the legal instrument.

It should be noted that the conflict between development and violation of legal norms has been noticed by scholars, who, for example, point to the relevance of legal analogy for its resolution [9]. Dvalishvili demonstrates a peculiar methodological approach, pointing to the abuse of law as a reservation of the legislator, who is unable to establish legal norms that can fairly regulate all the infinite variety of life situations. It is a kind of "valve" applied in the rarest situations of life [10].

In our opinion, the "abuse of law" should not be regarded only as a kind of "valve to let off steam". The mass character of this phenomenon is due to the total domination of the legislative form of regulation of relations, which, in the execution of "rigid" positivists, does not tolerate restrictions from the law.

The specifics of our country is that on the official level, the law is mainly identified with the law. The realities of a reality in need of development are such that the legislator is unable to establish legal norms capable of equitably regulating the infinite diversity of life situations, which are growing "by leaps and bounds. There is an urgent need for other forms of regulation which "incorporate" a process of self-regulation capable of taking adequate account of the benefits of diversity to the users themselves. The view of democracy as management of diversity seems very accurate [11].

Objectively, facts of going beyond the "most general schemes of development of legal relations" are becoming more frequent, which outwardly looks like "abuse of right" or 
violation of the law. This is a serious problem, and therefore we cannot agree with the opinion that the concept of "abuse of right" has no independent content [12].

We can assume that exceptions to the rules, because of their abundance, are themselves forced into rules. In this context, it is interesting to see the impact on international business of the increasing use of "exceptions" to WTO norms to justify trade measures to protect national industries and populations. Is there not an objective need here to "undermine the rules of global trade on which international business has relied for decades"? [13].

On the other hand, the situation provoked by COVID-19 requires "rapid response" solutions, when the regulatory qualities of the law are not able to promptly address the situation. The collision of fundamental rights and the right to health, objectively unavoidable in a coronavirus pandemic, requires government action to protect people's access to the health care system [14]. In this process, the collision of fundamental rights becomes a serious problem for the administration's managerial decisions, outwardly resembling an abuse of rights and generating numerous censures from "rule of law" enforcers.

Dvalishvili's thesis about the "rarity of life situations involving "abuse of law" is not confirmed [9]. In the work [6] the extension of this phenomenon to the area of electoral (public) legal relations is substantiated. The authors consider the problem of abuse of right during election campaigns: "...in practice there is the use of electoral technologies that do not formally violate legal norms (italics - our author), but cause significant damage" [6]. Another scholar, Akchurin, cites the technology of "candidate doubles" used to mislead voters [15].

\section{Conclusion}

In conclusion, we note that we need a different philosophy of relations to the "infinite variety of life situations", allowing it to develop and improve, rather than stagnate in the rigid embrace of a limited legislative form. There is an objective need for such law, which is not identified with law. We must frankly recognize the natural technological limitations of the legislative form and clarify the limits of its possible (permissible) application, beyond which the effectiveness of regulation towards the balanced development of the diversity of society is sharply reduced.

This means that in these spheres (beyond the natural reach of the legislative form) other methods of regulating behaviour and ordering relations are necessary. If this is not taken into account, the law can turn into an obedient instrument for the implementation of relatively private interest of certain influential individuals and groups that dominate the political space. And these seem to be the signs of an "abuse of right".

\section{References}

1. A.E. Naumov, Zloupotreblenie pravom: Teoretiko-pravovoy aspect [Abuse of Right: Theoretical and Legal Aspect], Synopsis of a PhD thesis in Legal Science (MGU Publ., Moscow, 2011)

2. V.P. Gribanov, Osushchestvlenie i zashchita grazhdanskikh prav [Implementation and Protection of Civil Rights] (Statut Publ., Moscow, 2000)

3. M. Stearns, Notre Dame L. Rev. 96(2), 447-512 (2021)

4. Grazhdanskoe pravo [Civil Law, ed. by E.A. Sukhanov, vol. 1] (VEK Publ., Moscow, 2003)

5. A.R. Akchurin, State Power and Local Self-Government, 11, 53-57 (2015)

6. E. Balayan, D.V. Gatsko, Russian Justice, 3, 61-64 (2020)

7. S.P. Stepkin, Rossiyskiy Yuridicheskiy Zhurnal, 1, 54-59 (2019) 
8. Federal Law of 02.05.2006 N 59-FZ (revised on 27.12.2018) "On the order of consideration of appeals of citizens of the Russian Federation”. Accessed on: 28 December, 2018. [Online]. Available: http://www.pravo.gov.ru

9. V. Mikryukov, Apuntes Universitarios, 11(1), 36-45 (2021). https://doi.org/10.17162/au.v11i1.544

10. L.Z. Dvalishvili, Magistrate Judge, 12, 36-40 (2018)

11. N. O’Brien, The Political Quarterly, 92(1) (2021). https://doi.org/10.1111/1467923X.12956

12. N.S. Malein, Yuridiheskaya otvetstvennost i spravedlivost [Legal Responsibility and Justice] (Yurid. Lit. Publ., Moscow, 1992)

13. L. Curran, J. Eckhardt, and J. Lee, Critical perspectives on international business, 17(5) (2021). https://doi.org/10.1108/cpoib-05-2020-0041

14. dos Santos JLG, Stein Messetti PA, Adami F, Bezerra IMP, Maia PCGGS, TristanCheever E and Abreu LCd, Front. Public Health 8:570243 (2021). https://doi.org/10.3389/fpubh.2020.570243

15. A.R. Akchurin, State Power and Local Self-Government, 5, 40-43 (2015) 